\title{
Revivalismo dos Cartazes de Cinema de 1946-1951
}

\author{
Mariana Ramos e Silva \\ Escola Superior de Media Artes e Design do Instituto Politécnico do Porto, Portugal \\ Vítor Quelhas \\ Escola Superior de Media Artes e Design do Instituto Politécnico do Porto, ID+ / uniMAD, Portugal
}

\begin{abstract}
The current project emerged from a partnership between the Master in Design and Arquivo Municipal da Póvoa de Varzim, where cinema posters between 1946-1951 were analized.

Depending on our state of mind or certain moment, it's perceived that it's constantly resorted to revivalism. And why? Is this the strength of innovation or just a longing desire? Starting from this idea, the objective of this study is the revivalism of the posters found, the return of these to the memory of viewers, as well as the impact on those who don't know them.

For such project, several researches around the cinema of this era were taken, such as a documentary analysis to dissect all that these posters had of relevant, from the theme, colours or fonts used.

Subsequently, an experimental / empirical investigation was undertaken, based on methodologies focused on design.

Accordingly in this phase of the project, some results were reached, as the combination of various typefaces in a fluid and cohesive way, with an easy reading, comprehension and attraction of each composition developed.

Thus, attractive information for each film proposal, it was possible to achieve unity in compositions, simultaneously legible and captivating for the public.
\end{abstract}

Keywords: Cinema, 1946-1951, Revivalism, Posters, Typography

\section{Introdução}

O presente projeto surgiu no âmbito da unidade curricular de Projeto de Design Pessoal, do $1 .^{\circ}$ ano do Mestrado em Design, da Escola Superior de Media Artes e Design do Instituto Politécnico do Porto, e com ponto de partida no Arquivo Municipal da Póvoa de Varzim. Foi lançado o desafio de pesquisar e analisar o Arquivo, e a partir daí encontrar uma temática do nosso interesse de modo a ser realizado um projeto de investigação, que poderia vir a ser explorado de forma prática.

Desta forma começou-se por analisar o inventário do Arquivo Municipal da Póvoa de Varzim, acabando por encontrar maior interesse na secção de Turismo, nos programas de espetáculos públicos. Dentro deste tema existiam diferentes cartazes ligados à Póvoa de Varzim, sendo escolhidos os de 1946 a 1951, ligados à área de Cinema do Teatro Garrett e da Póvoa Cine.

Com o interesse focado nos cartazes de cinema da Póvoa de Varzim começou-se a pensar numa forma de trazer de novo este conteúdo à memória dos espectadores, como um revivalismo, onde a forma como estes cartazes eram criados, utilizando apenas tipografia, era trazida de novo ao público.

Escolhido o ponto de partida para este projeto deu-se início a uma pesquisa de forma a aclarar a temática. Começou-se por clarificar o significado de revivalismo, assim como a diferença entre este e a nostalgia, de forma a criar uma ligação destes cartazes com o objetivo deste projeto, de recordar e reviver o passado junto do público numa época onde estes se encontram esquecidos.

A partir daqui abordou-se a publicidade e a forma como esta tem vindo a evoluir com o passar dos anos, fazendo uma ligação com o cinema, com o intuito de criar um vínculo entre os dois. Tendo sido também retratada a história do cartaz, assim como analisados os cartazes da Póvoa de Varzim.

Para o desenvolvimento deste projeto foi importante selecionar alguns filmes para que fosse possível recriar cartazes inspirados dos que foram selecionados no Arquivo. Desta forma foram escolhidos filmes que na época de 1946 a 1951 não existiam, como forma de trazer algo novo a este trabalho. Assim como filmes que nos dias de hoje eram tratados apenas com imagens, imagens com um grande caráter visual, que transformadas em texto iriam causar uma maior diferença e originalidade nos nossos dias. Assim sendo, foram selecionados géneros de ação, aventura e ficção científica, sendo posteriormente analisados e explicados na ótica deste projeto.

Tendo toda a pesquisa realizada começou-se por fazer uma investigação em volta da tipografia utilizada nos cartazes da Póvoa de Varzim, assim como em volta dos filmes escolhidos para trabalhar. Desta forma começou-se por desenvolver estudos de cartazes idênticos aos encontrados no Arquivo que, posteriormente, se foram desdobrando e evoluindo, com o intuito de os tornar mais contemporâneos.

\section{Desenvolvimento}

Este projeto começou com uma breve pesquisa e entendimento de alguns conceitos aliados ao revivalismo, à comunicação e ao cinema. Primeiramente tentou-se entender o que é o revivalismo e qual a sua diferença para nostalgia, pois estes eram o ponto de partida e a razão deste projeto.

Entende-se, portanto, que o revivalismo está intrinsecamente ligado ao passado, ao reviver aspetos passados com deslumbramento, com saudade. Para Michael Horowitz, o revivalismo é 
...uma ressurgência de valores espirituais e/ ou culturais dentro de uma cultura que percebe a si mesma como decadente (...) em resposta à crescente neutralização daqueles valores por uma cultura percebida como dominante ou em via de se tornar dominante (Mira 2014, 12).

Assim percebe-se que o revivalismo pode ser caracterizado como um movimento que vai surgindo em variadas alturas consoante as vivências que marcam cada época. Tal como nos diz Lídia Guedes, com o passar do tempo e da história percebemos que este "se trata de um fenómeno cíclico" e que normalmente surge em "períodos de pós-guerra, revoluções ou crises de natureza económica" (Mira 2014, 13).

Desta forma, entende-se então que o revivalismo surge como uma forma positiva onde o passado é revivido e desejado. Como uma vontade de procura pelo que outrora foi bom e que cada vez se torna mais saudoso e esperado, como uma forma de reconforto e revivência dos tempos que já foram vividos e que eram melhores que os do momento.

Ao contrário deste, mas ainda ligado a uma saudade e descontentamento que remete para o passado, tem-se a nostalgia. Esta mais ligada a emoções e sentimentos tristes e melancólicos. Esta saudade pode ser positiva ou negativa, caracterizada muitas das vezes como "agridoce" (Mira 2014, 14).

Estas são então duas palavras que apesar de diferentes a nível de significado, conseguem estar interligadas entre si. Apesar de uma ser ligada ao sentimento de saudade e alegria ou tristeza face a algo passado, e da outra ser um ato de reviver o passado que tanto nos fascina e traz saudade, ambas são consequência do desenvolvimento tecnológico e do acelerar da vida moderna. Acelerar este que nos nossos dias tanto nos pode ajudar a relembrar estes bons tempos do passado e nos despertar esta nostalgia e nos ajudar a comunicá-la, assim como nos pode fartar de toda esta mudança e evolução e nos aumentar o desejo dos tempos em que nada disso existia (Moreira 2011, 16) (Mira 2014, 15).

De seguida, abordou-se o tema da publicidade assim como a sua ligação ao cinema. Desde cedo que a comunicação é uma necessidade inerente do ser humano, utilizada como uma forma de educar e informar, que se ia alterando consoante o povo e a época inerentes. É uma forma de partilha de ideias e persuasão face os seres humanos que continuou vinculada até aos nossos dias. Como nos diz Mesquita,

O domínio do homem sobre a natureza e o mundo acentua-se e as formas de registo e suportes vão evoluindo paulatinamente. Todavia, em termos de comunicação exterior, tal como hoje a vemos e entendemos, pouca evolução teve ao longo dos séculos (Mineiro 2015, 9).

Como tal, a publicidade surge como uma forma de comunicação. Surge nos "primórdios", a partir do momento em que as pessoas sentiam necessidade de trocar produtos ou bens entre si, e de acordo com as necessidades e evolução humana foi-se desenvolvendo (Silva 2013, 4).

Desta forma percebe-se que a publicidade surge como um meio de comunicação que tende a captar a atenção dos consumidores, persuadindo com o intuito de fornecer informações sobre certos produtos. Para tal terá de conhecer e perceber quem será o seu público-alvo, sabendo o que aprecia, o que o caracteriza e em que meios se mobiliza, para que as estratégias de propaganda adotadas sejam as mais eficazes. A publicidade é assim uma forma de dar a conhecer, de educar e de informar, podendo mesmo incutir novas tendências e comportamentos na sociedade (Capinha 2016, 10).

Assim, entende-se que tudo na publicidade segue um pensamento estratégico de forma a atrair a atenção do consumidor a diferentes níveis. Desta forma, a persuasão é uma forte estratégia presente na publicidade no instante em que esta tende a estimular inconscientemente no consumidor desejos e necessidades. Segundo a teoria de Arrington, a publicidade apenas desperta desejos primários que já são intrínsecos no subconsciente de cada indivíduo através da informação transmitida (Campos 2014, 13).

O encanto do cinema está presente na ligação que este cria com o espectador, quer através da história contada, por ser tão próxima do real que mesmo sendo fantasia cria ligações entre as pessoas e as suas personagens ou determinados episódios, quer por toda a envolvência que se tem presente no cinema, desde a sala escura, o silêncio, à forma como o filme foi contruído. Todos estes aspetos são determinantes na captação da atenção do público. Desta forma percebe-se que o cinema mantém uma ligação com a publicidade, pois ambos transmitem mensagens e atraem o público. O cinema e a publicidade estiveram então desde cedo interligados, sendo este o primeiro suporte de publicidade audiovisual, através de filmes publicitários.

Posto isto, uma breve história e desenvolvimento do cartaz achou-se pertinente para este projeto, de modo a criar uma base e ligação para com toda a pesquisa em volta dos cartazes de cinema vistos no Arquivo.

Com a evolução do Homem, novas necessidades de comunicação foram surgindo e com o passar do tempo alterando-se e adaptando-se. O cartaz é um bom exemplo disso, surgindo de uma necessidade sociocultural de comunicar.

Por cartaz entende-se um suporte (podendo ser de variados suportes e formatos), onde são registadas determinadas informações relevantes para um público (Mineiro 2015, 10). Desta forma compreende-se que o cartaz é uma forma de comunicação, onde se partilha informação com o público com o intuito de transmitir uma determinada mensagem ou impulso.

Assim, percebe-se que os cartazes são uma parte integrante da publicidade, e que, tal como esta, se encontram em constante evolução consoante o meio onde se inserem. Como nos diz Barbosa,

...pode durante a sua existência, modificar-se tantas vezes quanto as necessárias para se adaptar a cada nova realidade com que convive (J. M. da R. Nogueira 2016, 30). 
Por conseguinte, os cartazes são um vínculo importante para a divulgação no cinema, tendo vindo a adaptar-se ao longo dos anos às novas realidades.

Os cartazes encontrados no Arquivo são a prova desta ligação de um cartaz com o cinema e a publicidade. Estes eram enviados para o público e continham informações acerca dos espetáculos que iriam decorrer nos teatros da Póvoa de Varzim, tanto do "Povoa-Cine" como do "Teatro Garrett". A primeira imagem destes cartazes que nos salta à vista, e que os caracteriza no Arquivo Municipal da Póvoa de Varzim, são as variadas cores que contêm, desde creme, cinza, amarelo, verde, azul (claro e escuro), cor-de-rosa, cor-de-laranja a magenta, assim como as suas pequenas dimensões (aproximadamente uma folha A4). Desta forma, era possível imprimir um maior número de cartazes, o que facilitava também o envio por correio a um maior número de famílias, conseguindo assim divulgar os programas de cinema de forma mais fácil e a todas as pessoas da cidade.

Para além da cor, da gramagem e qualidade do papel (com um tom transparente quase como um papel vegetal) é importante referir a principal característica destes cartazes - o uso da tipografia. A variedade de tipos de letra, habilmente conjugados, é algo que, hoje em dia, numa sociedade de valorização de imagens, já não se torna habitual. O facto é que estes cartazes só usam mesmo tipografia tradicional (letterpress), fazendo uso de vários tipos diferentes para hierarquizar e enfatizar os pontos chave da mensagem. Numa análise à tipografia destes cartazes percebe-se que esta é variada, tirando partido das diferentes morfologias e organizações, mas dentro de um certo limite, que seria o da época. Para além disso, verifica-se também que tiravam bastante partido dos tipos de letra utilizando não só variados num cartaz como misturados entre si para compor palavras.

A dificuldade presente neste género de cartazes está em conseguir captar a atenção do público para que o determinado filme tenha sucesso. Analisando alguns destes cartazes percebe-se que recorriam a algumas estratégias, como é o caso da repetição de algumas palavras, da exaltação dos filmes como sendo o melhor de sempre, o mais magnífico, formidável e impressionante (algumas das palavras utilizadas), da utilização de algumas palavras-chave separadas de todos os outros textos, do recorrer a frases ligadas aos dias vividos na época e do jogo de palavras que nalguns casos poderia levar ao humor.

Estas eram então as principais características destes cartazes dos anos de 1946 a 1951, as linhas retas simuladas por filetes, a cor de fundo e a variedade de tipos de letra utilizados, com diferenças nos pesos e corpos dos carateres para salientar a mensagem mais relevante. Estas características foram então o ponto de partida para o desenrolar deste projeto.

E foi desta forma que este projeto surgiu, e se iniciou uma exploração empírica, tendo por base metodologias focadas no design. Priorizou-se então a tipografia utilizada no Arquivo e tentou-se encontrar tipografias semelhantes às de alguns dos cartazes vistos. Esta seleção de tipos foi uma parte demorada, cuidada e pertinente neste projeto, pois era a cada tipo escolhido para as novas criações, que cabia manter uma ligação com a tipografia dos cartazes do Arquivo, só desta forma se alcançaria o revivalismo.

De seguida, passou-se à seleção dos filmes que iriam ser trabalhados. Para tal, achou-se pertinente fazer uma pesquisa em torno dos géneros cinematográficos dos filmes escolhidos, sendo abordados os géneros de ação, ficção-científica e aventura. Começou-se então pelos filmes de ação, que são dos mais frequentes, dos mais apreciados pelo público, e, consequentemente, os com mais êxito comercial. Sendo o seu principal objetivo propiciar ao espectador um momento prazeroso. Como características principais destes filmes encontram-se a fama do ator principal, que por si só já cativa o público, os efeitos especiais como forma atrativa e os cenários luxuosos e excêntricos que propiciam o fascínio e a fuga. Neste tipo de filmes predomina a simplicidade e dualidade entre o bem e o mal, o que leva a colocar as personagens ao serviço da ação (L. Nogueira 2010, 18). A seguir, o género de ficção-científica, que é caracterizado pelo uso da ciência em desenvolvimentos futuros, sendo entendido como uma forma de especulação em volta de variados mundos e acontecimentos, segundo determinadas suposições verdadeiras. Ou seja, na base deste género está a interrogação das repercussões dos avanços tecnológicos e científicos em torno do futuro da humanidade. As caraterísticas deste género são os cenários (cibernéticos, metropolitanos, espaciais ou apocalíticos), os objetos com design futurista e as personagens (aliens, robots, cyborgs e androides) que tentam idealizar o futuro da humanidade, com uma visão assente sobre a poluição, o sobreaquecimento ou a sobrepopulação (L. Nogueira 2010, 28). Por fim, mas não menos importante, os filmes de aventura, caracterizados pela descoberta, o exótico e o perigo presente nos variados cenários. Para além destes, o humor encontra-se sempre presente nos momentos de maior aflição dos protagonistas da história, estes vistos como heróis por seguirem sempre o desconhecido. Por último, outra característica presente neste tipo de filmes é o romantismo clássico que age como forma de acalmar todos os riscos que se desenrolam no decorrer das aventuras (L. Nogueira 2010, 51).

A razão pela escolha de filmes dentro destas categorias deve-se ao facto de estes serem filmes bastante presentes nos dias de hoje e onde a imagem e os efeitos especiais se encontram fortemente presentes, algo que não acontecia nos anos de 1946 a 1951. Desta forma, conseguia-se aumentar a dificuldade de traduzir toda a imagem em texto, misturando o passado com o futuro. Assim sendo, foram selecionados os filmes, Wonder Woman, Batman vs Superman - Dawn of Justice, Guardians of de Galaxy vol.2, Avengers Infinity War, Thor - Ragnarok e Aquaman, tendo sido feita uma pesquisa em torno das suas características e sinopses. Para além disto, os cartazes criados para a divulgação de cada um dos filmes, assim como os seus trailers, e comentários críticos encontrados na internet, foram uma mais valia para o aumento do conhecimento e inspiração para as criações dos cartazes finais. Estas 
foram então todas as bases de informação que deram origem a todos os elementos textuais presentes em cada um dos cartazes desenvolvidos.

Tendo os filmes selecionados, a tipografia característica dos cartazes da Póvoa de Varzim compreendidos nos anos de 1946 a 1951 e os textos que iriam caracterizar cada filme, passou-se à escolha das cores que iriam ser utilizadas em cada um dos cartazes criados, tendo por base as cores utilizadas nos cartazes encontrados no Arquivo. Assim sendo, para o cartaz da Wonder Woman foi selecionada a cor amarela, por esta ser uma cor que se encontra presente nos seus cartazes atuais, tanto no seu símbolo, como na sua roupa. Para o cartaz do Batman vs Superman - Dawn of Justice foi selecionada a cor cinza, pela simples razão de que este filme é muito ligado ao escuro, todos os seus cartazes contêm a predominância do preto e vermelho, porém não são cores presentes nos cartazes do Arquivo, pelo que se optou pela escolha de uma cor neutra como o caso do cinza. Para o cartaz dos Guardians of the Galaxy vol.2, foi selecionada a cor magenta, pela razão de todos os cartazes referentes a este filme conterem variados tons de cor ligadas ao rosa, roxo e azul. Para o cartaz dos Avengers Infinity War, foi escolhida a cor de laranja, um tom quase salmão, por ser a única cor, dentro de todas as selecionadas dos cartazes do Arquivo, que se aproximava mais às utilizadas nos cartazes deste filme, que eram bastante próximas das dos Guardians of the Galaxy vol.2. Para o cartaz do Thor - Ragnarok, selecionou-se a cor verde, pois após uma pesquisa aos cartazes deste filme verificou-se que as cores verde, vermelho e amarelo eram as mais presentes, sendo a verde a cor do seu rival e aliado Hulk. Por fim, para o cartaz do Aquaman, a escolha foi mais simples, dado que este é um super-herói com uma forte ligação ao mar, optou-se pela cor azul, que também se encontra bastante presente nos seus cartazes atuais.

Tendo terminada todas as principais seleções para cada um dos cartazes, iniciaram-se os estudos sobre a forma de composição destes. Começou-se então por desenhar cartazes seguindo a forma dos cartazes de cinema da Póvoa de Varzim, contento a mesma informação e distribuição. Nesta fase, foram analisadas todas as informações contidas nos cartazes, desde a colocação da informação do dia (dia da semana, dia do mês e mês) e local do filme no topo do cartaz, à sinopse, ou até à referência dos atores do filme. Contudo, com o desenrolar do projeto foi percebido que a simples "cópia" dos cartazes de cinema da Póvoa de Varzim levava a um resultado algo limitado, no sentido da previsibilidade, e que se deveria explorar mais a composição, mantendo na mesma a ideia de nostalgia presente em cada um deles, utilizando as mesmas tipografias, cores e forma de criação de textos.

Nesse sentido, selecionou-se um dos seis cartazes, o filme Thor - Ragnarok, e a partir deste iniciou-se um ciclo de experiências tendo sido testados variados cartazes de forma a aproximar-se cada vez mais das criações mais contemporâneas, de onde o trabalho tipográfico da designer Paula Scher, entre outros, serviu de inspiração.
O maior desafio ao longo deste processo de transformação dos cartazes foi o de encontrar um equilíbrio e conseguir manter o texto escrito, toda a tipografia da época, e mesmo assim ser legível e captar a atenção do público-alvo. Assim sendo, foi-se percebendo que, para alcançar uma composição mais contemporânea e relacionada ao passado, haviam determinadas informações que teriam de ser omitidas, para enfatizar a coesão e compatibilidade dos diversos elementos com o todo, contribuindo para a sensação de unidade que se aspirava, ao mesmo tempo que tornava a composição mais clara.

Deste modo, depois de diferentes experiências, chegou-se a uma solução final, que foi adaptada à linguagem gráfica dos restantes cartazes. Esta utilizando diferentes tipos de letra misturados entre si, tentando fazer referências com os pesos mais negros nas palavras mais importantes para obter uma ideia do filme, tal como era feito nos cartazes da Póvoa de Varzim. Desta forma conseguiu-se criar uma ligação a estes cartazes, usando a mesma lógica tipográfica, a mistura dos diversos tipos, os negros, as linhas e as cores, mas numa composição mais contemporânea, onde o uso da tipografia e o preenchimento de espaços foram mais trabalhados.

\section{Conclusão}

O mote para este projeto foram os cartazes de cinema da Póvoa de Varzim, vistos no Arquivo Municipal desta cidade. Com base nestes cartazes e numa breve caracterização destes, surgiu a motivação de retornar ao passado, de reavivar a memória de algumas pessoas, e ao mesmo tempo causar impacto junto das mais novas que os desconhecem, dando-os assim a conhecer.

Para sustentar esta ideia de projeto foi necessário fazer alguma pesquisa, tendo-se abordado o revivalismo, assim como a sua diferença entre nostalgia, a publicidade, incluindo a persuasão e o humor como base importante desta e a explicação da ligação entre a publicidade e o cinema, esta que já existe desde a existência do cinema. Para além destes pontos decidiu-se apresentar um pouco do desenvolvimento do cartaz, de forma a perceber-se melhor como este tem vindo a evoluir e, criando assim uma ligação aos cartazes da Póvoa de Varzim que foram retratados dentro deste tema. Como este projeto tinha como base os cartazes de cinema, foi necessário explorar alguns géneros cinematográficos, sendo abordados os que estavam ligados aos filmes escolhidos para trabalhar na parte prática deste projeto.

Desta forma, tendo toda a pesquisa feita seguiu-se para a parte prática do projeto, a parte de reviver os cartazes da Póvoa de Varzim, em composições mais contemporâneas. Esta foi então a parte mais desafiante deste projeto. Inicialmente com uma pesquisa em torno dos tipos de letra presentes em alguns dos cartazes vistos no Arquivo. Tendo esta fase terminada passouse a uma pesquisa envolto dos filmes escolhidos, pois estes seriam a base para todo o projeto. Desta forma, através de comentários, sinopses e trailers, conseguiu- 
se desenvolver diferentes manchas de texto que iriam ser o foco principal de cada cartaz. Esta foi a parte mais desafiante deste projeto, por ter de se conseguir representar e traduzir um filme em frases e ao mesmo tempo cativantes face ao público que iria ler. A relação entre forma e conteúdo tornava-se fundamental.

Com isto, passou-se ao desenvolvimento do projeto, quer isto dizer à criação dos cartazes. Começou-se por uma representação fidedigna aos cartazes da Póvoa de Varzim, e depois foi-se desenvolvendo e evoluindo cada cartaz até se aproximar aos nossos dias, utilizando sempre a mesma tipografia e cores. A partir daqui, neste momento de transformação e criação de cartazes mais contemporâneos, o projeto ganhou outra vida, tornando-se, ainda mais desafiante, devido a ter de se conseguir que cada mancha de texto fosse legível e ao mesmo tempo cativante.

Conclui-se que esta junção do antigo ao contemporâneo foi então a melhor decisão de todo este projeto e que alcançou os objetivos propostos. Foi um projeto que deu para explorar a tipografia e perceber que à medida que o tempo passa vai-se libertando e evoluindo cada vez mais dando espaço constante para novas explorações. Este projeto refletiu-se, não só numa evolução e revivalismo destes cartazes, das suas cores e tipografias, mas também numa evolução formativa, relacionada com os limites e aprendizagens. Foi recompensador perceber-se que se pode conceber projetos interessantes e atrativos utilizando apenas o potencial formal e expressivo da tipografia.

\section{Figuras}

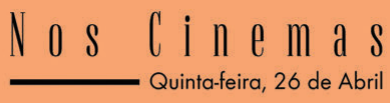

\section{AVENGERS}

INFINITY WAR

O Encontro dos Universos Chegou

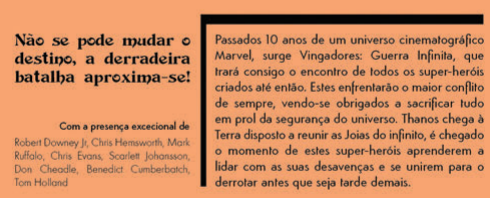

NÃO VAIS QUERER FUGIR DO FIM... JUNTA-TE AOS EXTRAORDINÁRIOS NÃO CAIAS NO ESQUECIMENTO!

Produçãa: Marvel Studios Direçăo: Joe Russo, Anthony Russo

Figura 1 - Exemplo de um dos primeiros cartazes criados

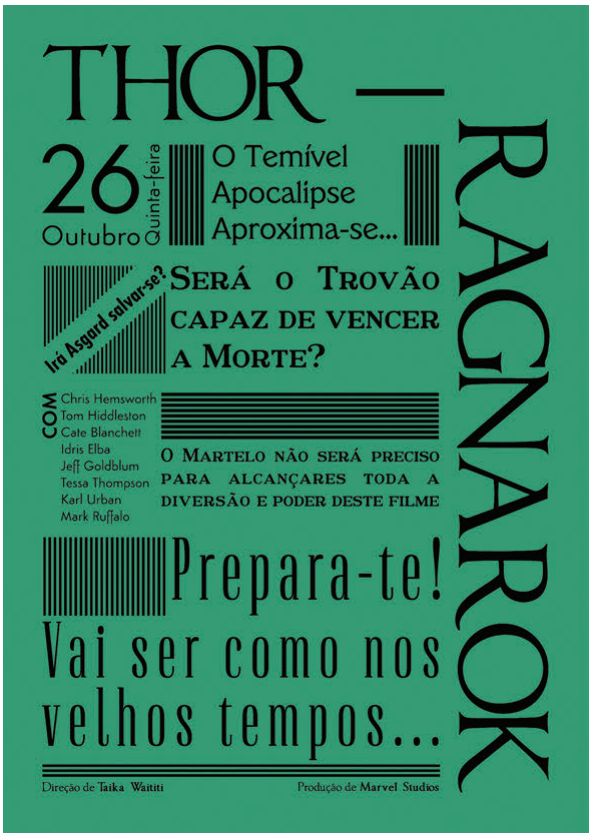

Figura 2 - Exemplo de um dos cartazes criados na fase de aproximação do contemporâneo

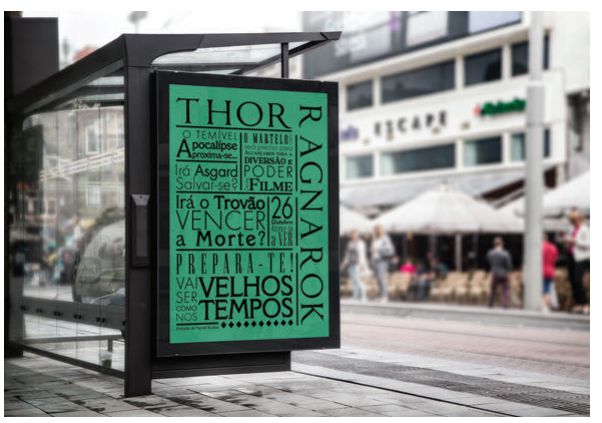

Figura 3 - Exemplo de um dos cartazes finais

\section{Bibliografia}

Campos, Ana Mafalda Jorge. 2014. "A PUBLICIDADE PARA O TURISMO INTERNO - PORTUGAL, QUE CAMINHO?" ESCOLA SUPERIOR DE COMUNICAÇÃO SOCIAL, Instituto Politécnico de Lisboa.

Capinha, Joana Isabel de Figueiredo. 2016. "O Contributo Do Humor Para a Publicidade Social O Caso Da Sociedade Ponto Verde." ESCOLA SUPERIOR DE COMUNICAÇÃO SOCIAL, INSTITUTO POLITÉCNICO DE LISBOA.

Mineiro, Joana Pimparel. 2015. "Cartazes Urbanos Acessíveis a Pessoas Cegas- Estratégias e Paradigmas de Interação." Universidade de Aveiro, Departamento de Comunicação e Arte.

Mira, Ana Isabel Falcão Trigoso Franco. 2014. "De Que 
Forma o Uso de Packaging Revivalista Contribui Para Aumentar a Percepção Da Qualidade e Genuinidade Das Marcas e Dos Seus Produtos." INSTITUTO POLITÉCNICO DE LISBOA ESCOLA SUPERIOR DE COMUNICAÇÃO SOCIAL.

Moreira, Ana Maio Gomes. 2011. "O IMPACTO DO REVIVALISMO DAS MARCAS NO CONSUMIDOR - Uma Perspetiva Aplicada a Algumas Marcas Dos Anos 80 Em Portugal." Universidade Católica Portuguesa.

Nogueira, José Mário da Rocha. 2016. "NOVAS DIMENSÕES PARA O CARTAZ." Universidade de Aveiro.

Nogueira, Luís. 2010. Manuais de Cinema II Géneros Cinematográficos. Edited by LabCom. Covilhã.

Silva, Ricardo André de Barros. 2013. "A Publicidade e Um Novo Género Masculino." ESCOLA SUPERIOR DE COMUNICAÇÃO SOCIAL, INSTITUTO POLITÉCNICO DE LISBOA. 